\title{
Detection of cathepsin B, cathepsin L, cystatin C, urokinase plasminogen activator and urokinase plasminogen activator receptor in the sera of lung cancer patients
}

\author{
QINGYONG CHEN $^{1 *}$, JUN FEI $^{1}$, LIJUN WU $^{1}$, ZHONGYONG JIANG $^{1}$, \\ YUQUAN WU ${ }^{1 *}, Y_{U N}$ ZHENG $^{1}$ and GUOHUA LU ${ }^{2}$ \\ ${ }^{1}$ Department of Respiratory Disease, The 117th Hospital of PLA, Zhejiang 310013; ${ }^{2}$ Department of Respiratory Disease, \\ First Affiliated Hospital, College of Medicine, Zhejiang University, Zhejiang 310004, P.R. China
}

Received December 16, 2010; Accepted March 17, 2011

DOI: 10.3892/ol.2011.302

\begin{abstract}
The present study aimed to determine the levels of cathepsin B (cath B), cathepsin L (cath L), cystatin C, urokinase plasminogen activator (u-PA) and urokinase plasminogen activator receptor (u-PAR) in the sera of patients with lung cancer compared to healthy controls using ELISA. Concomitantly, the relationship between the components and clinicopathological prognosis was analyzed. The study included 30 healthy volunteers and 105 lung cancer patients. Blood samples were collected and cath B, cath L, cystatin C, u-PA and u-PAR measurements were made using ELISA. Results showed that the levels of cath B, cath L, cystatin C, u-PA and u-PAR were significantly higher in the patient group compared to the healthy controls. The significance was marked for cath B and mild for u-PAR in correlation with lymph node metastasis. There was no significance for other parameters. Notably, patients with a combination of high cystatin $\mathrm{C}$ and high cath B levels had significantly lower survival probability as compared to those with cystatin $\mathrm{C}^{+} /$cath $\mathrm{B}^{-}$or with cystatin $\mathrm{C}^{-} /$cath $\mathrm{B}^{-}$. Similarly, patients with a combination of high u-PA and u-PAR experienced significantly shorter survival. Furthermore, the univariate analysis revealed that cath B, u-PAR, lymph node metastases, stage and grade were related
\end{abstract}

Correspondence to: Dr Qingyong Chen, Department of Respiratory Disease, The 117th Hospital of PLA, Hangzhou, Zhejiang 310013, P.R. China

E-mail: cqyong117@163.com

*Contibuted equally

Abbreviations: cath B, cathepsin B; cath L, cathepsin L; NSCLC, non-small cell lung cancer; ELISA, enzyme-linked immunosorbent assay; u-PA, urokinase plasminogen activator; u-PAR, urokinase plasminogen activator receptor

Key words: cathepsin B, cathepsin L, cysteine C, urokinase plasminogen activator, urokinase plasminogen activator receptor, lung cancer, progonosis, sera to survival. However, findings of the multivariate Cox analysis indicated that the sera levels of cath B, u-PAR and lymph node metastases may serve as independent prognostic variables in patients with lung cancer.

\section{Introduction}

Cathepsins are members of the lysosomal cysteine proteases family and are usually located inside a lysosome. Numerous studies showed a correlation of increased proteolytic activity of cysteine cathepsins with neoplastic transformation, tumor invasion and metastasis through the destruction of extracellular matrix components and basement membranes in tumor spread. Cathepsin B (cath B) is able to activate pro-urokinasetype plasminogen activator and enhance subsequent plasmin generation. Increased levels of cath B and L were observed in tissues of primary and metastatic tumors in a number of cancer types (1-3). The serum level of cath B may serve as a prognostic factor for patients with advanced melanoma. By contrast, the serum level of cath $L$ was not statistically different in the control, non-metastatic and metastatic patient groups (3). Moreover, using immunohistochemical analysis, the overexpression of cath $\mathrm{B}$ and $\mathrm{L}$ was shown to correlate with more aggressive tumor behavior, early relapse and shorter survival (2). However, in lung cancer tissue, cath L did not reveal any association with prognosis (4).

Cystatin $\mathrm{C}$, an accurate marker of glomerular filtration rate and endogenous cysteine protease inhibitor, has been found in a variety of human tissues, but is mainly found in extracellular body fluid and serum. Increased levels of cystatin $\mathrm{C}$ in tumor tissues were shown to correlate with a favourable prognosis of cancer patients (5), whereas higher levels of cystatin $\mathrm{C}$ in body fluids have been associated with a poor prognosis of cancer patients (6). In contrast, in squamous-cell lung cancer, no alteration in the cystatin $\mathrm{C}$ protein level was described in matched pairs of normal and tumor tissue homogenates (7).

Plasminogen activation is a proteolytic cascade that leads to tumor invasion. Urokinase plasminogen activator (u-PA) is released from cells as a virtually inactive single polypeptide chain proenzyme, pro-u-PA, which is linked to its receptor 
(u-PAR) at the cell membrane and then converted to active two-chain u-PA. u-PAR is a glycolipid-anchored cell surface protein which specifically binds pro-u-PA and u-PA. The binding of u-PA and u-PAR strongly enhances the activation of plasminogen into plasmin, which plays both a direct role on the extracellular matrix degradation and an indirect role by activating other matrix metalloproteinases (8).

Overexpression of u-PA and u-PAR was reported in tissue extracts of lung cancer, but results on the progonosis of these components remain controversial. Studies showed that high levels of u-PA mRNA using Northern blot analysis were associated with metastasis, whereas protein content by ELISA analysis did not show any significant relationship with patient outcome (9). Moreover, these samples were mostly from tumor tissue extracts, containing stromal and epithelial cells, which did not provide exact information on the level of the cell proteins and relative contribution to tumor progression (10).

To the best of our knowledge, correlation of the levels of these proteases in cancer patients with the outcome of the disease has yet to be determined. This study aimed to determine the sera levels of these proteases and to study their relationship with various clinicopathological prognostic variables. Moreover, whether the elevation of certain proteases is relevant to the malignancy of lung cancer, particularly prognosis, was examined.

\section{Materials and methods}

Subjects. This study was performed on 30 healthy volunteers and 105 patients with lung cancer. Samples were collected between March and October 2004 at the First Affiliated Hospital and the 117th Hospital of PLA in Hangzhou, Zhejiang, China. The use of serum was approved by the local ethics committee, and the patients gave informed consent. Clinical and pathological data were rendered anonymous.

The healthy volunteers comprised 17 males and 13 females aged 12 to 71 years (median 52.4). They were judged to be healthy on the basis of their medical history. None of the volunteers suffered from any infectious disease at least 1 month prior to the collection of blood samples. None had ever undergone any treatment for cancer or other chronic diseases, such as diabetes, hypertension or rheumatoid arthritis. Hematological and biochemical blood tests were within normal limits.

The patient group comprised 70 males and 35 females aged 45 to 81 years (median 55.3). Tumor histology and stages were classified according to the WHO classification and the TNM staging system of the UICC, respectively. In all treated patients, therapy was completed at least 6 months prior to admission into the study. No patient underwent any chronic disease treatment for at least 6 months prior to blood sample collection. Hematological and biochemical blood tests were within normal limits.

Sample collection. Blood samples were obtained by venipuncture from fasting subjects between 09:00 and 10:00 h under standard conditions. Samples were clotted at $4-8^{\circ} \mathrm{C}$ and centrifuged at 3,000 rpm for $10 \mathrm{~min}$. The serum thus collected was distributed in aliquots of $500 \mu \mathrm{l}$ each and stored at $-80^{\circ} \mathrm{C}$ until analysed.
Table I. Concentrations ( $\mathrm{ng} / \mathrm{ml}$ ) of cath B, cath $\mathrm{L}$, cystatin C, $\mathrm{u}-\mathrm{PA}$ and u-PAR in the sera of healthy controls and patients with lung cancer.

\begin{tabular}{lcccc}
\hline Variable & $\begin{array}{c}\text { Healthy control } \\
(\mathrm{n}=30)\end{array}$ & & $\begin{array}{c}\text { Lung cancer } \\
(\mathrm{n}=105)\end{array}$ & P-value \\
\cline { 2 - 2 } & Mean $\pm \mathrm{SD}$ & & Mean $\pm \mathrm{SD}$ & \\
\hline Cathepsin B & $6.21 \pm 2.05$ & & $10.65 \pm 2.48$ & $<0.001$ \\
Cathepsin L & $19.77 \pm 0.58$ & & $26.16 \pm 6.52$ & $<0.001$ \\
Cystatin C & $2.45 \pm 0.49$ & & $3.91 \pm 0.64$ & $<0.001$ \\
u-PA & $37.93 \pm 7.34$ & & $47.36 \pm 21.03$ & $<0.001$ \\
u-PAR & $299.76 \pm 95.9$ & & $429.36 \pm 122.85$ & $<0.001$ \\
\hline
\end{tabular}

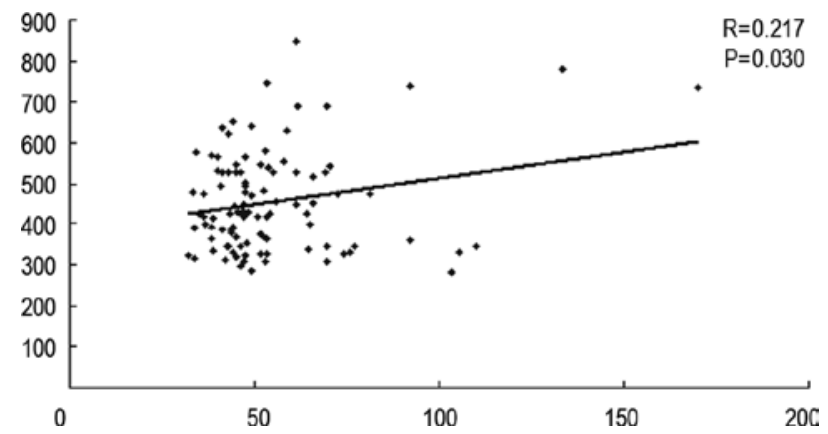

Figure 1. Relationship between the serum levels of u-PA and u-PAR in 105 patients with lung cancer.

ELISAs. Antigen levels were measured by using the enzymelinked immunoadsorbent assay (ELISA) based on the sandwich principle as previously described (11). Measurements of cath $\mathrm{B}$, cath $\mathrm{L}$, cystatin $\mathrm{C}$, u-PA and $\mathrm{u}-\mathrm{PAR}$ in the sera using ELISA were performed according to the manufacturer's instructions. Each assay was performed in duplicate.

Statistical analysis. Differences between groups were statistically examined using the Kruskal-Wallis test. The Pearson's regression analysis was performed to evaluate the correlation among the components. Survival curves were calculated by the Kaplan-Meier method. Statistical significance was tested by the log-rank test between subgroups of patients. The Cox proportional hazards was used for multivariate analysis. $\mathrm{P}<0.05$ was considered to be statistically significant.

\section{Results}

Detection of cathepsin B, cathepsin L, cystatin $C, u$-PA and $u$-PAR in the sera of patients with lung cancer. The levels of cath B, cath L, cystatin C, u-PA and u-PAR measured in 105 serum samples from patients with lung cancer prior to treatment commencing and from 30 healthy controls are shown in Table I. Compared to the healthy controls, the levels of cath B, cath L, cystatin C, u-PA and u-PAR were significantly increased in the sera of lung cancer patients. These results indicate a possible role for these enzymes in tumor growth and progression. 


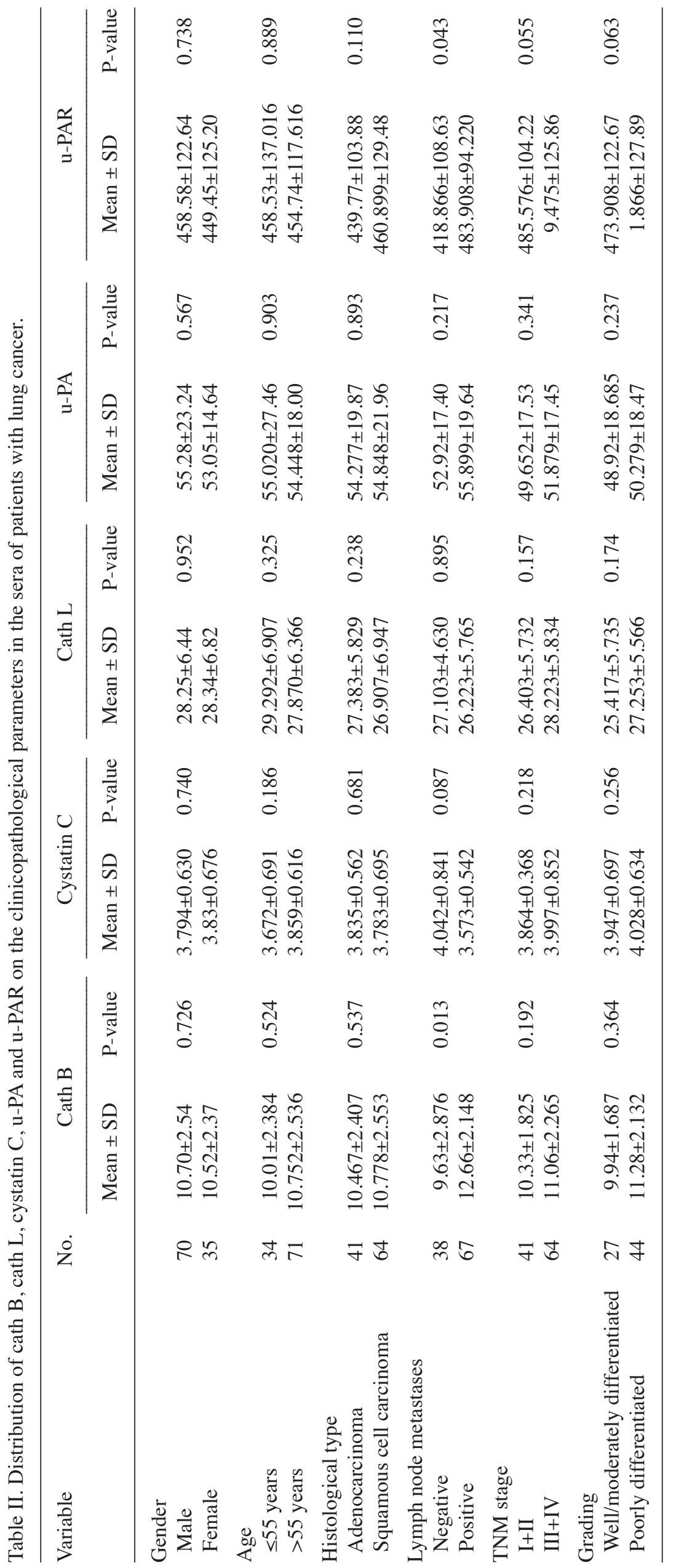


Table III. Univariate and multivariate analysis of cath B, cath L, cystatin C, u-PA, u-PAR and other potential factors for prognosis in patients with lung cancer.

\begin{tabular}{|c|c|c|c|c|c|c|}
\hline \multirow[t]{2}{*}{ Variables } & \multirow[t]{2}{*}{ No. } & \multirow{2}{*}{$\begin{array}{l}\text { Overall survival } \\
\text { (months) }\end{array}$} & \multicolumn{2}{|c|}{ Univariate analysis } & \multicolumn{2}{|c|}{ Multivariate analysis } \\
\hline & & & $\begin{array}{l}\text { P-value } \\
\text { (log-rank) }\end{array}$ & $\mathrm{RR}$ & $\begin{array}{c}\text { P-value } \\
\text { (log-rank) }\end{array}$ & RR \\
\hline \multicolumn{7}{|l|}{ Cathepsin B } \\
\hline$>9.985 \mathrm{ng} / \mathrm{ml}$ & 53 & 24.3 & 0.032 & 2.08 & 0.026 & 2.25 \\
\hline$\leq 9.985 \mathrm{ng} / \mathrm{ml}$ & 52 & 30.2 & & & & \\
\hline \multicolumn{7}{|l|}{ Cystatin C } \\
\hline$>3.91 \mathrm{ng} / \mathrm{ml}$ & 54 & 25.9 & 0.056 & 1.47 & 0.061 & 1.35 \\
\hline$\leq 3.91 \mathrm{ng} / \mathrm{ml}$ & 51 & 28.3 & & & & \\
\hline \multicolumn{7}{|l|}{ Cathepsin L } \\
\hline$>26.16 \mathrm{ng} / \mathrm{ml}$ & 56 & 26.7 & 0.578 & 1.03 & 0.412 & 1.04 \\
\hline$\leq 26.16 \mathrm{ng} / \mathrm{ml}$ & 49 & 28.6 & & & & \\
\hline \multicolumn{7}{|l|}{$\mathrm{u}-\mathrm{PA}$} \\
\hline$>47.36 \mathrm{ng} / \mathrm{ml}$ & 52 & 26.7 & 0.863 & 1.02 & 0.766 & 1.02 \\
\hline$\leq 47.36 \mathrm{ng} / \mathrm{ml}$ & 53 & 28.1 & & & & \\
\hline \multicolumn{7}{|l|}{ u-PAR } \\
\hline$>429.36 \mathrm{ng} / \mathrm{ml}$ & 50 & 25.2 & 0.041 & 1.85 & 0.046 & 1.66 \\
\hline$\leq 429.36 \mathrm{ng} / \mathrm{ml}$ & 55 & 29.9 & & & & \\
\hline \multicolumn{7}{|l|}{ Gender } \\
\hline Male & 70 & 28.1 & 0.574 & 0.95 & 0.664 & 0.97 \\
\hline Female & 35 & 26.3 & & & & \\
\hline \multicolumn{7}{|l|}{ Age } \\
\hline$\leq 55$ years & 34 & 28.2 & 0.631 & 1.06 & 0.671 & 1.03 \\
\hline$>55$ years & 71 & 26.4 & & & & \\
\hline \multicolumn{7}{|l|}{ Histological type } \\
\hline Adenocarcinoma & 41 & 28.2 & 0.476 & 1.08 & 0.522 & 1.05 \\
\hline Squamous cell carcinoma & 64 & 26.5 & & & & \\
\hline \multicolumn{7}{|l|}{ Lymph node metastases } \\
\hline Negative & 38 & 32.4 & 0.015 & 2.50 & 0.022 & 2.31 \\
\hline Positive & 67 & 24.5 & & & & \\
\hline \multicolumn{7}{|l|}{ TNM stage } \\
\hline $\mathrm{I}+\mathrm{II}$ & 41 & 30.1 & 0.048 & 1.62 & 0.146 & 1.13 \\
\hline III+IV & 64 & 26.3 & & & & \\
\hline \multicolumn{7}{|l|}{ Grading } \\
\hline Well/moderately differentiated & 71 & 28.9 & 0.042 & 1.68 & 0.191 & 1.12 \\
\hline Poorly differentiated & 34 & 25.3 & & & & \\
\hline
\end{tabular}

$\mathrm{RR}$, relative risk.

Levels of cathepsin B, cathepsin L, cystatin $C, u-P A$ and $u$-PAR in relation to clinicopathological parameters. The relationships between the levels of these proteases in the sera of patients with lung cancer and their clinicopathological parameters were analyzed. As shown in Table II, the levels of cath $\mathrm{L}$ and $\mathrm{u}-\mathrm{PA}$ were not related to any of the clinicopathological parameters. By contrast, the level of cath B was found to be significantly correlated with the lymph node metastasis $(\mathrm{P}=0.013)$. The level of u-PAR was also mildly related to the lymph node metastasis $(\mathrm{P}=0.043)$. Although not statistically significant, a trend $(\mathrm{P}=0.087)$ was particularly observed between the cystatin $\mathrm{C}$ level and the lymph node status. A significant correlation was found between $\mathrm{u}-\mathrm{PA}$ and $\mathrm{u}-\mathrm{PAR}$ (Fig. 1) ( $\mathrm{r}=0.217 ; \mathrm{P}=0.030)$. However, no significant correlation was observed between cath $\mathrm{B}$ level and cath $\mathrm{L}$ or cystatin $\mathrm{C}$ (data not shown).

Correlation of the sera of cathepsin B, cathepsin L, cystatin $C$, $u-P A$ and $u-P A R$ with prognosis. The median values were used to dichotomize the levels of cath $\mathrm{B}$, cath $\mathrm{L}$, cystatin $\mathrm{C}$, $\mathrm{u}-\mathrm{PA}$ and u-PAR to study their prognostic relevance by univariate and multivariate analysis (Table III). For each of the five parameters, overall survival was compared for patients with levels below and equal to or above the median 


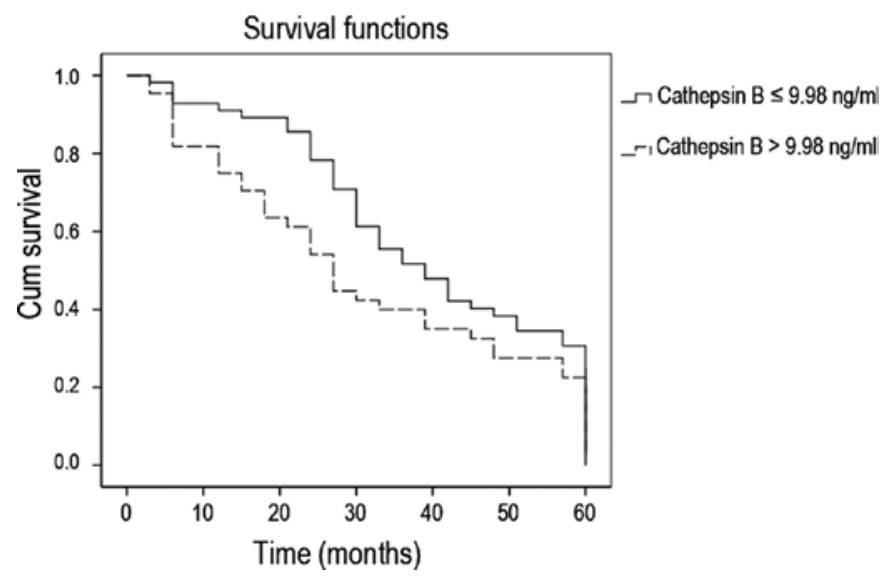

Figure 2. Prognostic significance of cath B in the sera of patients with lung cancer. Survival probability rate was calculated according to the KaplanMeier method. A median level of $9.985 \mathrm{ng} / \mathrm{ml}$ was used as a cut-off value to divide patients into low- and high-cath B groups. P-value was calculated using the log-rank test. The number of patients at risk is indicated.

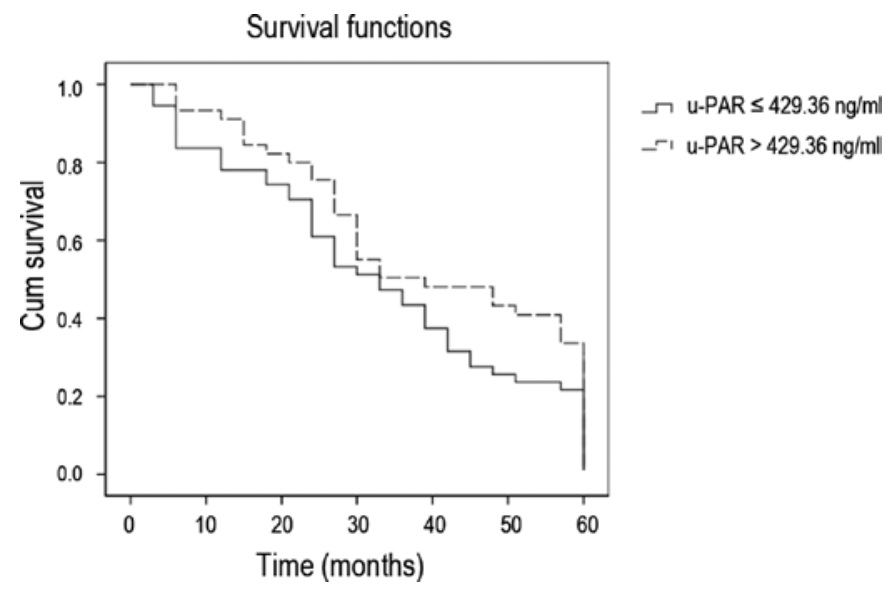

Figure 3. Prognostic significance of u-PAR in the sera of patients with lung cancer. A median level of $429.36 \mathrm{ng} / \mathrm{ml}$ was used as a cut-off value to divide patients into low- and high-u-PAR groups.

values. Using this cut-off value, cath $\mathrm{B}$ significantly predicted survival [relative risk $(\mathrm{RR})=2.08, \mathrm{P}=032$ ]. As noted from the Kaplan-Meier curves (Fig. 2), the probability of survival of patients with lower levels of cath B was more favorable than for patients with higher levels. u-PAR levels also correlated significantly with survival in this patient population, although its prognostic impact was lower than that for cath $B(R R=1.85$; $\mathrm{P}=0.041$ ) (Fig. 3). A similar but statistically not significant trend was observed for cath $\mathrm{L}$, cystatin $\mathrm{C}$ and $\mathrm{u}-\mathrm{PA}$.

Moreover, we focused on whether the combination of variables was likely to increase the prognostic stratification of the patients. Median values were used as a cut-off value for these parameters. Kaplan-Meier curves of the cath B/ cystatin $\mathrm{C}$ combinations are shown in Fig. 4. Patients with both factors above the cut-off point (median) had significantly lower survival probability, as compared to those with cystatin $\mathrm{C}^{+} /$cath $\mathrm{B}^{-}(\mathrm{RR}=1.83, \mathrm{P}=0.046)$ or with cystatin $\mathrm{C}^{-} /$ cath $\mathrm{B}^{-}(\mathrm{R} R=2.74, \mathrm{P}=0.015)$. Similarly, patients with both $\mathrm{u}-\mathrm{PA}$ and u-PAR-positive experienced moderately shorter

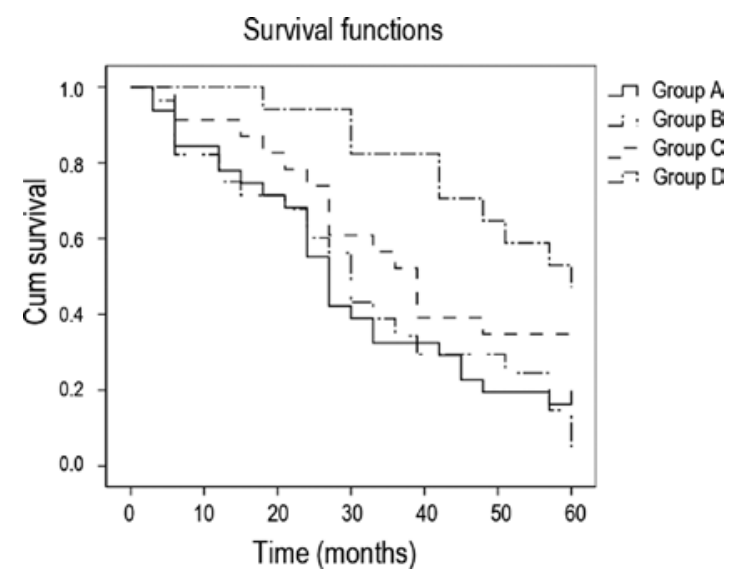

Figure 4. Impact of the combination of cath B and cystatin C levels in the sera on the overall survival of 105 patients with lung cancer. Group $A(n=22)$ : low expression of cath $B$ and cystatin $C(R R=2.74, P=0.015)$; group $B(n=30)$ : low expression of cath $\mathrm{B}$ and a high expression of cystatin $\mathrm{C}(\mathrm{RR}=1.83, \mathrm{P}=0.046)$; group $\mathrm{C}(\mathrm{n}=29)$ : low expression of cystatin $\mathrm{C}$ and a high expression of cath $\mathrm{B}$ $(\mathrm{RR}=1.04, \mathrm{P}=0.637)$; and group $\mathrm{D}(\mathrm{n}=24)$ : high expression of cath $\mathrm{B}$ and cystatin C. P-value was calculated by the log-rank test compared to group $\mathrm{D}$. The number of patients at risk is indicated.

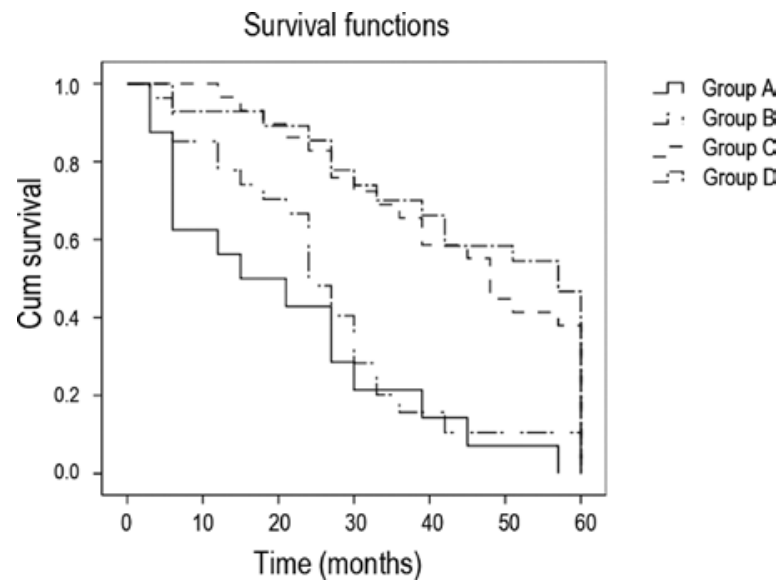

Figure 5. Impact of the combination of u-PA and u-PAR levels in the sera on the overall survival of 105 patients with lung cancer. Group A $(n=19)$ : low expression of $\mathrm{u}-\mathrm{PA}$ and $\mathrm{u}-\mathrm{PAR}(\mathrm{RR}=2.35, \mathrm{P}=0.026)$; group $\mathrm{B}(\mathrm{n}=36)$ : low expression of $\mathrm{u}-\mathrm{PAR}$ and a high expression of $\mathrm{u}-\mathrm{PA}(\mathrm{RR}=2.24, \mathrm{P}=0.028)$; group $\mathrm{C}(\mathrm{n}=34)$ : low expression of $\mathrm{u}-\mathrm{PA}$ and a high expression of $\mathrm{u}-\mathrm{PAR}$ $(\mathrm{RR}=1.08, \mathrm{P}=0.452)$; and group $\mathrm{D}(\mathrm{n}=16)$ : high expression of $\mathrm{u}-\mathrm{PA}$ and $\mathrm{u}-\mathrm{PAR}$ as the control group.

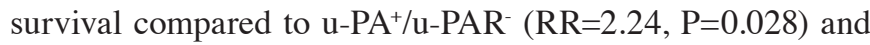
u-PA-/u-PAR- (RR=2.35, P=0.023) (Fig. 5). By contrast, the combination of cath $\mathrm{L}$ and cystatin $\mathrm{C}$ or the combination of cath $\mathrm{B}$ and u-PA had no overall prognostic significance as compared to each individual factor (data not shown).

The final model of the univariate and multivariate Cox analyses using death from all causes as the endpoint is shown in Table III. Untivariate analysis revealed that cath B, u-PAR, malignancy grade, clinical stages and lymph node metastasis were identified as independent prognostic parameters. However, multivariate analysis revealed that only cath B, u-PAR and lymph node metastasis were identified as independent prognostic parameters. Clinical stage, age, histological classification, gender, malignancy grade, cath L, cystatin C 
and $\mathrm{u}$-PA as constant parameters were not independent markers of poor outcome.

\section{Discussion}

A number of clinical studies have been performed to evaluate the diagnostic and prognostic significance of high levels of cysteine proteases cath $\mathrm{B}$ and $\mathrm{L}$ in tumor cytosols (12). It has been shown that patients with higher content or increased proteolytic activity of cath B in primary lung tumors exhibited significantly higher risk of recurrence or death than patients with a low content of the enzyme (13). In breast cancer, the prognostic impact of cath $\mathrm{L}$ was shown to be comparable to that of lymph node status (2). However, the role of cathepsins in the serum of cancer patients remains unclear.

An increased expression and release of cath $B$ has been detected in various tumor tissues as well as in the sera of tumor patients (14). Retrospective immunohistochemical analysis revealed that patients who had cath B-positive tumors are characterized by a significantly shorter survival compared to patients who had cath B-negative tumor tissues (4). Moreover, results of another study showed that lung cancer patients with an up-regulation of cath $\mathrm{B}$ tended to have higher rates of haematogenous and intrapulmonary metastases (15). One reason for this poor prognosis may be the high concentration of cath B at the periphery of the tumor cell foci, indicating that these areas were possibly involved in the process of tumor cell invasion. In addition, a significant increase of the cath B activity in tumor-infiltrated lymph nodes was observed compared to non-infiltrated regional lymph nodes, which also impaired patient survival (16). Consistent with these data, results of our study showed that the levels of cath B were significantly increased in the sera of lung cancer patients as compared to those in healthy controls. Non-small cell lung cancer (NSCLC) patients with high levels of cath B had a more frequent metastasis compared to patients with low levels of cath B. Our results showed that cath B is markedly involved in the mechanism of tumor cell invasion and metastasis.

Compared to the control serum levels, cath $\mathrm{L}$ was also elevated in primary lung cancer patients, whereas increased cath L levels did not correlate with any of the clinicopathological parameters. This finding is consistent with the immunohistochemical study of Cordes et al (17), which showed the weakest expression and staining intensity for cath $\mathrm{L}$ in lung cancer among the cathepsins. These findings support the hypothesis that the role of cath $\mathrm{L}$ in lung cancer progression and metastasis is less important than that proposed for other tumors (15).

It has been suggested that in cancer, the increased levels of cysteine protease activity, which are not balanced by a corresponding increase of cysteine protease inhibitors, are involved in the remodelling and degradation of extracellular matrix proteins, a proteolytic event associated with tumor spread, invasion and metastasis. An enhanced expression of cystatins is expected to diminish the tumor-associated proteolytic activity and evidence indicates a suppressive role of tumor-associated cystatins in various types of cancer (18). In the present study, the levels of cystatin $\mathrm{C}$ were elevated in primary lung cancer patients. However, increased cystatin $\mathrm{C}$ levels did not correlate to any of the clinicopathological parameters. These observations are in contrast to previous findings in other types of cancer, in particular in colorectal cancer, in which the level of cystatin $\mathrm{C}$ is an independent prognostic factor of relapse-free survival (19).

The analysis of the relationship of the variables with the survival probability using Kaplan-Meier models revealed the most significant prognostic value for cath $\mathrm{B}$. Patients with high cath B serum levels were associated with significantly lower survival probability rates as compared with patients with low cath B levels. A strong prognostic impact of cath B is consistent with previous findings, confirming the association of its overexpression with the metastatic potential of lung cancer cells. Results of this study did not show any prognostic value for the levels of cath $\mathrm{L}$ and cystatin $\mathrm{C}$. For cystatin $\mathrm{C}$, the median survival of patients with low levels is apparently longer than that of patients with high levels, but the difference is not statistically significant. The lack of cystatin $\mathrm{C}$ and cath $\mathrm{L}$ prognostic impact in the serum is contrary to results obtained in tissue cytosols of the head and neck (7) and breast tumors (2). This event has yet to be elucidated.

The levels of u-PA and u-PAR in malignant tumors have been found to be correlated with patient prognosis (8). For example, in breast cancer high u-PA levels are independent and significant prognostic markers for poor relapse-free and overall survival. Furthermore, a high level of u-PAR is associated with a poor prognosis. In lung cancer, the role of the u-PA system is less clear. u-PA was found to be a prognostic marker when detected with immunohistochemistry, and to be correlated with tumor size, nodal status and advanced stage (20). Using ELISA, no significant relationship was found between u-PA and overall survival (21). These latter studies also investigated the role of other components of the u-PA system in subgroups of patients with NSCLC using ELISA, and showed a significant relationship between u-PAR and poor prognosis in squamous-cell carcinoma. In large-cell carcinoma of the lung, none of the components of the u-PA system were significantly associated with prognosis (10). The differences in results between the studies on the prognostic value of the u-PA system in NSCLC may be explained by the small sizes of the histological subgroups and by the differences in patient groups and methods used.

Our present study results showed that both serum u-PA and u-PAR levels in patients with lung cancer were significantly higher than those in healthy controls. However, the levels of u-PA did not correlate with any of the clinicopathological parameters. By contrast, the levels of serum u-PAR were higher in patients with lymph node metastases than in those without metastases. This observation is well-correlated with earlier studies whose findings showed that the u-PA-u-PAR system played a crucial role in the invasion and metastasis of lung cancer cells (22).

Of note is whether the elevations of serum u-PA and/or u-PAR concentrations are associated with the poor prognosis of lung cancer patients. In concordance with previous studies (10), we found that the overall survival rate of lung cancer patients with simple serum u-PAR elevation, or both serum u-PA and u-PAR elevation, was significantly lower than that of patients with normal levels of u-PA and u-PAR, but serum u-PA was not a marker of independent prognosis. In this series, a significant correlation has also been found between 
$\mathrm{u}-\mathrm{PA}$ and $\mathrm{u}-\mathrm{PAR}$. These findings indicate that a combination measurement of serum u-PA and u-PAR may provide additional information in determining prognosis.

We aimed to further determine whether the combination of variables would increase the prognostic stratification of the patients, using median values as a cut-off value for these parameters. We found that patients with high levels of cath $\mathrm{B}$ and cystatin $\mathrm{C}$ experienced significantly lower survival probability as compared to other combinations or with prognostic values of individual variables. Similarly, the patients with high levels of u-PA and u-PAR experienced significantly shorter overall survival. By contrast, combinations of other parameters exhibited no marked prognostic significance as compared to each parameter individually. Our results support recent data showing that cystatin $\mathrm{C}$ and cath $\mathrm{B}$ or $\mathrm{u}-\mathrm{PA}$ and $\mathrm{u}-\mathrm{PAR}$ interaction may participate in the modulation of the invasive phenotype of human tumors $(8,23)$.

In the multivariate Cox analysis, we statistically weighed cath B, cath L, cystatin C, u-PA and u-PAR activity with these established factors to assess their relative prognostic impact. Lymph node metastasis remained the most powerful predictor of survival for NSCLC patients; cath B and u-PAR activity also proved to be independent prognostic factors. However, clinical stage, age, histological classification, gender, malignancy grade, cath L, cystatin $\mathrm{C}$ and u-PA as constant parameters were not independent markers of poor outcome.

In conclusion, our preliminary study showed an association of higher serum levels of cath $\mathrm{B}$, cath $\mathrm{L}$, cystatin $\mathrm{C}$, $\mathrm{u}-\mathrm{PA}$ and $\mathrm{u}-\mathrm{PAR}$ with the lung cancer patient group. Moreover, the prognostic significance of cath B and u-PAR has been defined, revealing a strong correlation of higher levels of the two enzymes, with a shorter survival rate of lung cancer patients. In addition, the combination measurement of five parameters may provide additional information in determining prognosis.

\section{Acknowledgements}

This study was supported by the Funds of the Nanjing Command Health Speciality '122' Engineering (Fund no. 342510001). We would like to thank Dr Jun Cheng for the technical assistance and discussion.

\section{References}

1. Sloane BF, Herman CJ and Padarathsingh M: Molecular mechanisms of progression and metastasis of human tumors: a pathology B study section workshop. Working Report from the Division of Research Grants, NIH. Cancer Res 54: 5241-5245, 1994.

2. Thomssen C, Schmitt M, Goretzki L, et al: Prognostic value of the cysteine proteases cathepsins B and cathepsin L in human breast cancer. Clin Cancer Res 1: 741-746, 1995.

3. Kos J, Stabuc B, Schweiger A, et al: Cathepsins B, H, and L and their inhibitors stefin A and cystatin $\mathrm{C}$ in sera of melanoma patients. Clin Cancer Res 3: 1815-1822, 1997.

4. Kayser K, Richter N, Hufnagl P, Kayser G, Kos J and Werle B: Expression, proliferation activity and clinical significance of cathepsin B and cathepsin L in operated lung cancer. Anticancer Res 23: 2767-2772, 2003
5. Kos J and Lah TT: Cysteine proteinases and their endogenous inhibitors: Target proteins for prognosis, diagnosis and therapy in cancer (Review). Oncol Rep 5: 1349-1361, 1998.

6. Kos J, Werle B, Lah T and Brunner N: Cysteine proteinases and their inhibitors in extracellular fluids: markers for diagnosis and prognosis in cancer. Int J Biol Markers 15: 84-89, 2000.

7. Krepela E, Prochazka J, Karova B, Cermak J and Roubkova H: Cysteine proteases and cysteine protease inhibitors in non-small cell lung cancer. Neoplasma 45: 318-331, 1998.

8. Andreasen PA, Kjoller L, Christensen L and Duffy MJ: The urokinase-type plasminogen activator system in cancer metastasis: a review. Int J Cancer 72: 1-22, 1997.

9. Pedersen H, Grondahl-Hansen J, Francis D, et al: Urokinase and plasminogen activator inhibitor type 1 in pulmonary adenocarcinoma. Cancer Res 54: 120-123, 1994.

10. Pedersen H, Brunner N, Francis D, et al: Prognostic impact of urokinase, urokinase receptor, and type 1 plasminogen activator inhibitor in squamous and large cell lung cancer tissue. Cancer Res 54: 4671-4675, 1994.

11. Kos J, Smid A, Krasovec M, et al: Lysosomal proteases cathepsins D, B, H, L and their inhibitors stefins A and B in head and neck cancer. Biol Chem Hoppe Seyler 376: 401-405, 1995.

12. Schmitt M, Janicke F, Moniwa N, Chucholowski N, Pache L and Graeff H: Tumor-associated urokinase-type plasminogen activator: biological and clinical significance. Biol Chem Hoppe Seyler 373: 611-622, 1992

13. Sukoh N, Abe S, Ogura S, et al: Immunohistochemical study of cathepsin B. Prognostic significance in human lung cancer. Cancer 74: 46-51, 1994

14. Kos J, Nielsen HJ, Krasovec M, et al: Prognostic values of cathepsin B and carcinoembryonic antigen in sera of patients with colorectal cancer. Clin Cancer Res 4: 1511-1516, 1998.

15. Fujise N, Nanashim A, Taniguchi Y, et al: Prognostic impact of cathepsin B and matrix metalloproteinase-9 in pulmonary adenocarcinomas by immunohistochemical study. Lung Cancer 27: 19-26, 2000.

16. Werle B, Kraft C, Lah TT, et al: Cathepsin B in infiltrated lymph nodes is of prognostic significance for patients with nonsmall cell lung carcinoma. Cancer 89: 2282-2291, 2000.

17. Cordes C, Bartling B, Simm A, et al: Simultaneous expression of Cathepsins $\mathrm{B}$ and $\mathrm{K}$ in pulmonary adenocarcinomas and squamous cell carcinomas predicts poor recurrence-free and overall survival. Lung Cancer 64: 79-85, 2009.

18. Cox JL, Sexton PS, Green TJ and Darmani NA: Inhibition of B16 melanoma metastasis by overexpression of the cysteine proteinase inhibitor cystatin C. Melanoma Res 9: 369-374, 1999.

19. Kos J, Krasovec M, Cimerman N, Nielsen HJ, Christensen IJ and Brunner N: Cysteine proteinase inhibitors stefin A, stefin $\mathrm{B}$, and cystatin $\mathrm{C}$ in sera from patients with colorectal cancer: relation to prognosis. Clin Cancer Res 6: 505-511, 2000.

20. Robert C, Bolon I, Gazzeri S, Veyrenc S, Brambilla C and Brambilla E: Expression of plasminogen activator inhibitors 1 and 2 in lung cancer and their role in tumor progression. Clin Cancer Res 5: 2094-2102, 1999.

21. Salden M, Splinter TA, Peters HA, et al: The urokinase-type plasminogen activator system in resected non-small-cell lung cancer. Rotterdam Oncology Thoracic Study Group. Ann Oncol 11: 327-332, 2000.

22. Almasi CE, Hoyer-Hansen G, Christensen IJ and Pappot H: Prognostic significance of urokinase plasminogen activator receptor and its cleaved forms in blood from patients with non-small cell lung cancer. Acta Pathol Microbiol Immunol Scand Suppl 117: 755-761, 2009.

23. Corticchiato O, Cajot JF, Abrahamson M, Chan SJ, Keppler D and Sordat B: Cystatin C and cathepsin B in human colon carcinoma: expression by cell lines and matrix degradation. Int J Cancer 52: 645-652, 1992. 